\title{
Erratum to: Performance analysis of non-traditional algorithmic parameters in machining operation
}

\author{
R. Gayatri ${ }^{1}$ • N. Baskar ${ }^{2}$
}

Published online: 2 November 2015

(C) Springer-Verlag London 2015

Erratum to: Int J Adv Manuf Technol (2015) 77:443-460

DOI 10.1007/s00170-014-6452-9

The original version of this article unfortunately contained a mistake. The following is the list of errors and their corresponding correct presentation.

\begin{tabular}{|c|c|c|c|}
\hline Page number & $\begin{array}{l}\text { Location/Column } \\
\text { and line number }\end{array}$ & Incorrect & Correct \\
\hline 1 & Author's affiliation & $\begin{array}{l}\text { R. Gayatri }(*) \text { : N. Baskar } \\
\text { Saranathan College of Engineering, } \\
\text { Tiruchirapalli, Tamil Nadu, India } \\
\text { e-mail: gayatri_cst@yahoo.com } \\
\text { N. Baskar } \\
\text { e-mail: baskarnaresh@yahoo.co.in }\end{array}$ & $\begin{array}{l}\text { R. Gayatri (*) } \\
\text { Department of Computer Applications, J.J.College } \\
\text { of Engineering and Technology, Tiruchirapalli, } \\
\text { Tamil Nadu, India } \\
\text { e-mail: gayatri_cst@yahoo.com } \\
\text { N. Baskar } \\
\text { Department of Mechanical } \\
\text { Engineering, Saranathan College } \\
\text { of Engineering, Tiruchirapalli, Tamil Nadu, India } \\
\text { e-mail: baskarnaresh@yahoo.co.in }\end{array}$ \\
\hline 1 & Abstract & $\begin{array}{l}\text { (Chen and Tsai, Int J Prod Res } \\
\text { 34:2803-2825, 1996) }\end{array}$ & $\begin{array}{l}\text { (Chen and Sai, Int J Prod Res } \\
\text { 34:2803-2825, 1996) }\end{array}$ \\
\hline 4 & Col 1, line 15 & $\begin{array}{l}\text { The parameters and constraints are } \\
\text { identified from }\end{array}$ & \\
\hline
\end{tabular}

The online version of the original article can be found at http://dx.doi.org/ 10.1007/s00170-014-6452-9.

R. Gayatri

gayatri_cst@yahoo.com

N. Baskar

baskarnaresh@yahoo.co.in

1 Department of Computer Applications, J.J.College of Engineering and Technology, Tiruchirapalli, Tamil Nadu, India

2 Department of Mechanical Engineering, Saranathan College of Engineering, Tiruchirapalli, Tamil Nadu, India 
(continued)

the mathematical model proposed

by Chen et al. [6].

Col 1, line 25

Table 1

Col 2, line 3

Col 2, line 20

16

Col 1, line 1

Table 24 column title

Table 25, column 1
The objective of this optimization model [6] is

Table 1 Cutting model data of Chen and Tsai [6]

The tables below show the corresponding feed, speed, and depth values obtained in SA for cutting model by Chen et al.[6].

The tables below show the corresponding feed, speed, and depth values obtained in PSO for the cutting model by Chen et al. [6]. multi-pass turning operation [6].

No. of iterations

SA/SS [6]
The parameters and constraints are identified from the mathematical model proposed by Chen et al. [1].

The objective of this optimization model [1] is Table 1 Cutting model data of Chen and Tsai [1]

The tables below show the corresponding feed, speed, and depth values obtained in SA for cutting model by Chen et al.[1].

The tables below show the corresponding feed, speed, and depth values obtained in PSO for the cutting model by Chen et al. [1]. multi-pass turning operation [1].

Unit $\operatorname{cost}(\$)$

$\mathrm{SA} / \mathrm{SS}[1]$ 